J. Amer. Soc. Hort. Sci. 115(2):251-255. 1990.

\title{
Prolonged Storage of Lemons Using Individual Seal-packaging
}

\author{
E. Cohen, S. Lurie, B. Shapiro, S. Ben-Yehoshua, Y. Shalom, and I. Rosenberger \\ Department of Fruit and Vegetable Storage, Agricultural Research Organization, Volcani Center, \\ Bet Dagan 50250, Israel
}

Additional index words. postharvest, senescence, plastic film, citrus fruit, Citrus lirnon

\begin{abstract}
Eureka' lemons [Citrus limon (L.) Burro. f.] treated for commercial storage were held for 6 months at 13C. One-half of the fruits were individually sealed in high-density polyethylene (HDPE) plastic film and half not sealed. The HDPE-seaIed lemons showed little change in the water relations characteristics, while unsealed lemons lost weight and decreased in water potential throughout the storage period. The maturity indices in the two treatments were generally similar during the first 3 months of storage, after which maturation of wrapped fruit was slower than that of the control. The overall marketable quality of the fruit was higher in HDPE-sealed lemons than in unsealed. From these results, it appears feasible to introduce seal packaging in packing lines where lemons will be placed in extended storage.
\end{abstract}

In Israel, the bulk of the lemon crop matures in early winter, while the consumer demand for fresh lemons exists year-round. Optimal storage for lemon is at $13 \mathrm{C}$ to avoid chilling injury (Cohen and Schiffmann-Nadel, 1978), but long-term storage at that temperature leads to fruit senescence and fungal decay. Methods to extend the marketing period of lemon are needed. Storage for 6 months at 2C with intermittent warming has been tried commercially during recent years, with some success (Cohen, 1988; Cohen et al., 1983). Attempts have also been made to delay maturation and prolong the harvest season through the use of gibberellin sprays, with negative results thus far (Cohen et al., 1979; Gallasch, 1981).

Favorable results with quality retention during storage between 14 and $21 \mathrm{C}$ have been achieved with various citrus fruits wrapped or seal-packaged with polyethylene films. Wrapping or sealing individual grapefruit in polyethylene film reduced transpirational water loss and deformation (Albrigo and Fellers, 1983; Ben-Yehoshua et al, 1979, 1981; Hale et al., 1981; Kawada and Hale, 1980; Kawada and Albrigo, 1979; Purvis, 1983a). Seal-packaging also delayed normal deterioration and increased the storage and shelf life of the fruit (Albrigo and Ismail, 1983; Ben-Yehoshua, 1985; Burger and Davis, 1986; Purvis, 1983b; Stein, 1986). High-density polyethylene (HDPE) wraps delayed loss of firmness and peel coloration of lemons for up to 6 months with the fruit kept at 17 to 20C (Ben-Yehoshua et al, 1983; Sharkey et al., 1985). Wrapping grapefruit

Received for publication 23 Nov. 1988. Contribution no. 2533 E, 1988 series, from the Agricultural Research Organization, The Volcani Center, Bet Dagan, Israel, The cost of publishing this paper was defrayed in part by the payment of page charges. Under postal regulations, this paper therefore must be hereby marked advertisement solely to indicate this fact. with HDPE film also accelerated wound healing caused during mechanical harvesting (Golumb et al., 1984). Another beneficial effect of seal-packaging of citrus was the containment of decayed fruit to single, sealed units (Barmore et al., 1983; Sharkey and Peggie, 1984; Tugwell and Gillespie, 1981).

One problem of introducing seal-packaging into packinghouses has been that major modifications must be made in the packing line to avoid waxing the fruit. Waxed fruit that also was seal-packaged was found to accumulate ethanol and off flavors (Albrigo and Fellers, 1983; Albrigo and Ismail, 1983; Purvis, 1983a). Our study was designed to see whether waxed and seal-packaged lemons accumulate high levels of ethanol; whether their gas exchange, as monitored by respiration and ethylene production, is significantly affected by this treatment; and to determine the physiological behavior of nonsealed and HDPE-sealed mature green winter lemons during 6 months of storage. Changes related to fruit water relations and fruit senescence also were monitored.

\section{Materials and Methods}

Green 'Eureka' lemons of uniform size, averaging $60 \mathrm{~mm}$ in diameter, originating from three separate groves, were obtained from a packinghouse after conventional treatment, which included washing, disinfection with sodium ortho-phenylphenate (SOPP), and treatment with Britex storage wax that incorporated the fungicides imazalil $(0.03 \%)$ and thiabendazole (TBZ) $(0.05 \%)$. One-half of the fruit from each grove were individually sealpackaged in 10- $\mu$ m-thick HDPE plastic film, and the other half were left nonsealed as the control. The permeability rates of the film at $20 \mathrm{C}$ were (all $\mathrm{ml} / \mathrm{m}^{2}$ per $24 \mathrm{hr}$ ) 0.42 for water, 5400 for $\mathrm{O}_{2}$, and 2200 for $\mathrm{CO}_{2}$. 
All the fruit was placed in storage in $20-\mathrm{kg}$ plastic boxes at 13C and $90 \% \mathrm{RH}$. Each month, three $20 \mathrm{-kg}$ boxes from each treatment (each box representing one grove) were removed from storage and held for an additional week at 17C. After this week, water status and stage of maturity of the fruit were examined. Fruit weight loss, firmness, diameter, peel (albedo and flavedo) thickness, and peel water potential were measured. In addition, fruit color and $\mathrm{CO}_{2}$, and ethylene production were measured as well as juice titrable acidity, electrolyte conductivity, ethanol, and acetaldehyde. Fruit blemishes and rots were also evaluated.

Fruit water relations. Weight loss was determined by weighing 180 fruit from each treatment (60 from each replicate) at the beginning of storage. Each month, the fruit were weighed again and 30 fruit from each treatment (10 from each replicate) were removed for shelf-life evaluation. After 1 week at $17 \mathrm{C}$, fruit firmness was determined with a compression tester using a 5-kg weight (Ben-Yehoshua et al., 1983). Full deformation was measured $30 \mathrm{sec}$ after exerting the force on the fruit-the firmer the fruit, the lower the reading. The water potential was measured on three disks from the peel of 30 fruit, 15 per treatment, using a J14 leaf press (Campbell Scientific Inc., Logan, Utah). Disks of fruit were pressed and the reading made at the first sign of juice at the cut edges. After fruit weight loss was recorded, fruit diameter was measured and the fruit were cut in half and the thickness of the albedo and flavedo measured with calipers.

Fruit maturity. Fruit color was measured on three replicates of 10 lemons from each treatment using a Gardner XL20 colorimeter (Bethesda, Md.) by reading the "a" value (Ben-Yehoshua et al., 1983). Ethylene and $\mathrm{CO}_{2}$ production from the fruit after color measurement were determined by placing each replicate in 4-liter jars at $20 \mathrm{C}$ using three replicates per treatment. The jars were closed for $1 \mathrm{hr}$, after which gas samples were removed with a syringe. Ethylene and $\mathrm{CO}_{2}$ concentration were determined by gas chromatography, using a Poropak $\mathrm{N}$ column at ambient temperature and a TCD detector for $\mathrm{CO}_{2}$, and an alumina column at 35C and a FID detector for ethylene. Juice was extracted from three replicates of 10 lemons per treatment and juice content expressed as percent of fruit weight. Acidity was determined by titrating an aliquot of juice against $0.1 \mathrm{~N} \mathrm{NaOH}$ and expressing the result as citric acid. Electrolyte content was measured on a conductometer (El-Hama Instruments, Ramat HaGotan, Israel). Ethanol and acetaldehyde were determined from the head space of a 10-ml aliquot of the juice enclosed in a 50-ml Erlenmeyer flask and incubated on a shaker for $7 \mathrm{~min}$. A 1-ml sample of the head space was withdrawn and measured using a gas chromatography. The column was 20M carbowax TPA on Chromosorb 80/100; the injector was set at $110 \mathrm{C}$, the column at $80 \mathrm{C}$, and the FID detector at $180 \mathrm{C}$.

\section{Results and Discussion}

Sealing individual lemons in HDPE film reduced weight loss significantly and preserved firmness, as expressed by deformation tests (Fig. 1 A and B). During storage, nonsealed lemons lost $\approx 10$ times as much weight as HDPE-sealed lemons. After 6 months of storage at $13 \mathrm{C}$, plus 1 week at $17 \mathrm{C}$, the nonsealed lemons had lost $29 \%$ of their initial weight. Lemons that lost $>5 \%$ of their weight began to look dry, which occurred in nonsealed lemons within 1 month of storage. The sealed fruit maintained their firmness throughout storage and shelf life, and did not lose $>3 \%$ of their initial weight. Appearance and, therefore, marketability of waxed citrus fruit are impaired when weight loss exceeds 5\% (Albrigo and Ismail, 1983), resulting in a soft,

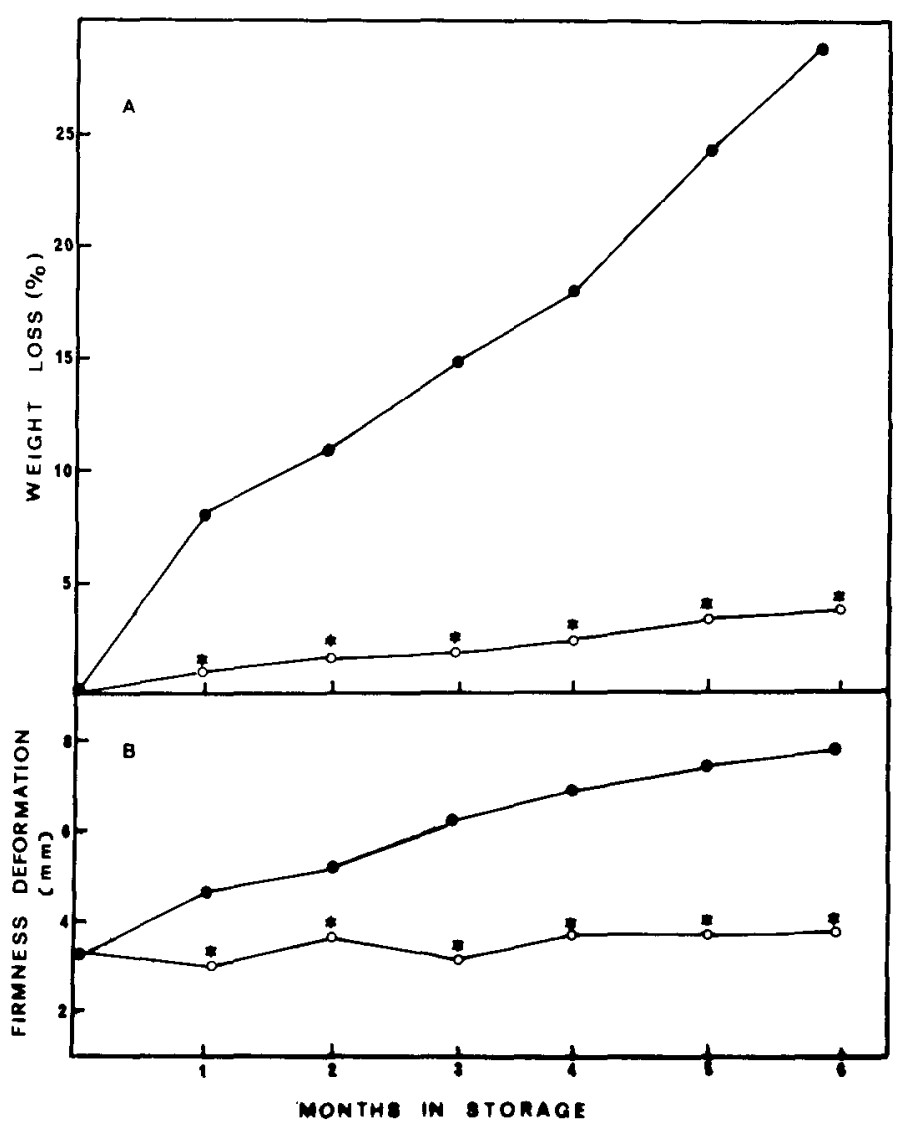

Fig. 1. Effect of seal-packaging in HDPE film on lemons stored at $13 \mathrm{C}$ for 1 to 6 months, followed by 1 week at 17C. (A) Weight loss expressed as percent of initial weight. (B) Firmness expressed as millimeters of deformation. $\cdot=$ nonsealed; $O=$ seal-packaged. *Significant differences between treatments, $P=0.05$.

senescent peel that usually becomes deformed in the shipping container (Hale et al., 1981; Kawada and Albrigo, 1979). Therefore, a major benefit of the HDPE film on lemons during storage was the significant reduction in weight loss.

Nonsealed fruit had lower values for water potential than HDPE-sealed fruit (Fig. 2). After 6 months of storage at 13C and 1 week at $17 \mathrm{C}$, nonsealed fruit had a water potential of - 3.1 MPa, compared with - 1.1 MPa at harvest. Sealed fruit had a water potential of $-1.9 \mathrm{MPa}$ after 6 months, $40 \%$ of the change of the nonsealed fruit.

As fruit weight decreased, there was a decrease in diameter (Fig. 3A), with a subsequent deformation of the fruit. After 6 months of storage at $13 \mathrm{C}$ and 1 week at $17 \mathrm{C}$, diameter had decreased $4 \mathrm{~mm}$ in nonsealed fruit since harvest, but that of sealed fruit showed no change. Shriveling of the fruit was reflected in the level of the fruit packed in the carton: in cartons of non-sealed fruit it was lower than in seal-packaged fruit.

While flavedo thickness showed no significant change during storage in either sealed or nonsealed fruit, albedo thickness was significantly less in nonsealed fruit after 4 months of storage and subsequently (Fig. 3B). Albedo thickness decreased by $\approx .50 \%$ in the nonsealed fruit, from an average of $4.1 \mathrm{~mm}$ at harvest to $2.4 \mathrm{~mm}$ after 6 months of storage and 1 week of shelf life. This decrease accounts for almost all the change in fruit diameter that occurred as the result of extensive weight loss during storage.

All the changes in fruit water status, weight loss, firmness, 


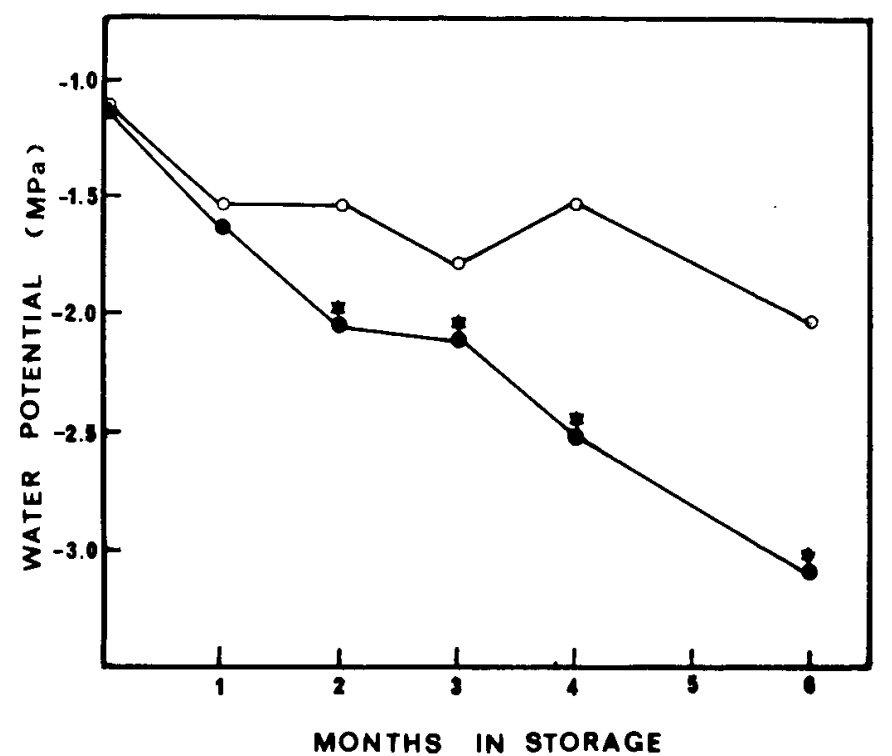

Fig. 2. Effect of seal-packaging in HDPE film on the water potential of lemons stored at $13 \mathrm{C}$ for up to 6 months, followed by 1 week at $17 \mathrm{C}$. $\bullet=$ nonsealed; $O=$ seal-packaged. ${ }^{*}$ Significant differences between treatments, $P=0.05$.

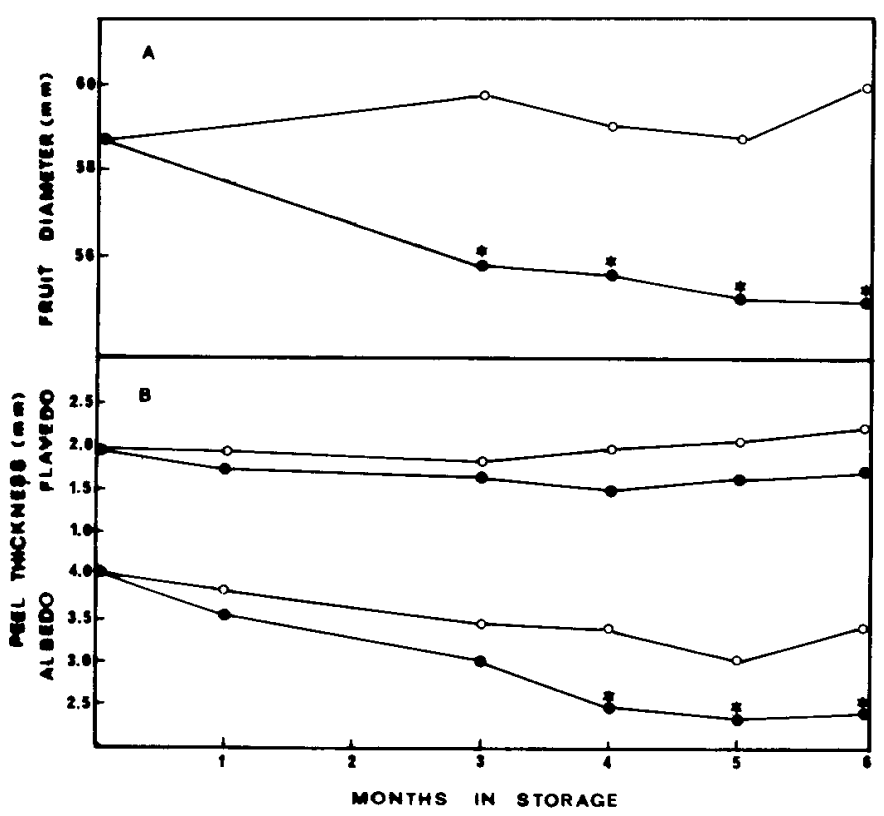

Fig. 3. Effect of seal-packaging in HDPE film on lemons stored at $13 \mathrm{C}$ for 1 to 6 months, followed by 1 week at 17C. (A) Fruit diameter. (B) Thickness of the peel albedo and flavedo. $-=$ nonsealed; $O=$ seal-packaged. ${ }^{*}$ Significant differences between treatments, $P=0.05$.

and peel water potential and thickness were greatly reduced by seal-packaging the lemons in HDPE film. Since transpiration contributes most to the postharvest deterioration of citrus fruit (Ben-Yehoshua, 1969), more attention has been given to controlling it than respiration. Lemons have a relatively high transpiration coefficient and, therefore, benefited from conditions that reduced water loss. High-humidity storage was shown to increase their storage potential (Sharkey and Peggie, 1984), and the main effect of HDPE seal-packaging is to maintain a high in-package humidity (Ben-Yehoshua et al., 1983).
Color of the lemons at harvest was dark to light green with the "a" value averaging - 15 (Fig. 4). All sealed and nonsealed fruit had turned yellow by the end of 2 months of storage at $13 \mathrm{C}$ plus 1 week at $17 \mathrm{C}$. The seal-packaged lemons showed greater variability in color development than nonsealed lemons, but the differences generally were not significant. After 6 months of storage plus 1 week of shelf life, nonsealed fruit had "a" values ranging from 1.6 to 2.9 , and those of seal-packaged fruit ranged from 0.7 to 2.9 .

The percentage of juice and the acid content of the juice changed during storage (Fig. $5 \mathrm{~A}$ and B). The percent of juice showed a steady increase in both nonsealed and sealed lemons during the first 3 months of storage plus shelf life. After the 3rd month of storage, the amount of juice remained relatively constant in sealed fruit, while that in nonsealed lemons increased significantly during the 4th month of storage and then began to decline. After 6 months of storage at $13 \mathrm{C}$ plus 1 week at $17 \mathrm{C}$, there was no significant difference in the percent of juice from the two treatments. Lemons are considered mature for export when they contain $28 \%$ juice by volume (Sinclair, 1984), regardless of peel color. An increase in both juice content and acidity normally occurs during storage in lemons, as well as limes (Eaks and Masias, 1965), in contrast to other edible citrus cultivars, and is a sign of their increasing maturity.

The acidity of nonsealed lemons increased as storage time progressed, reaching a plateau after 5 months of storage plus shelf life (Fig. 5B). In sealed lemons there was an increase in acidity during the first 2 months, followed by a decrease. The acidity of the sealed lemons after 6 months of storage at 13C plus 1 week a $17 \mathrm{C}$ was slightly lower than at harvest. This lack of increase in acidity in the seal-packaged lemons should not be a problem if the lemons are harvested with a high acid level.

The acetaldehyde level was similar in both treatments throughout storage (Fig. 6A). It remained low for the first 4 months of storage at $13 \mathrm{C}$ plus 1 week at $17 \mathrm{C}$; during the 5 th month there was a rise in acetaldehyde, followed by a decrease.

The ethanol content of the lemon juice was similar in both treatments during the first 3 months of storage and showed little change (Fig. 6B). After 3 months of storage, the ethanol content began to rise in the nonsealed lemons, whereas, in the sealed lemons, the ethanol level remained stable throughout storage.

There was no change in the juice electrolyte conductivity

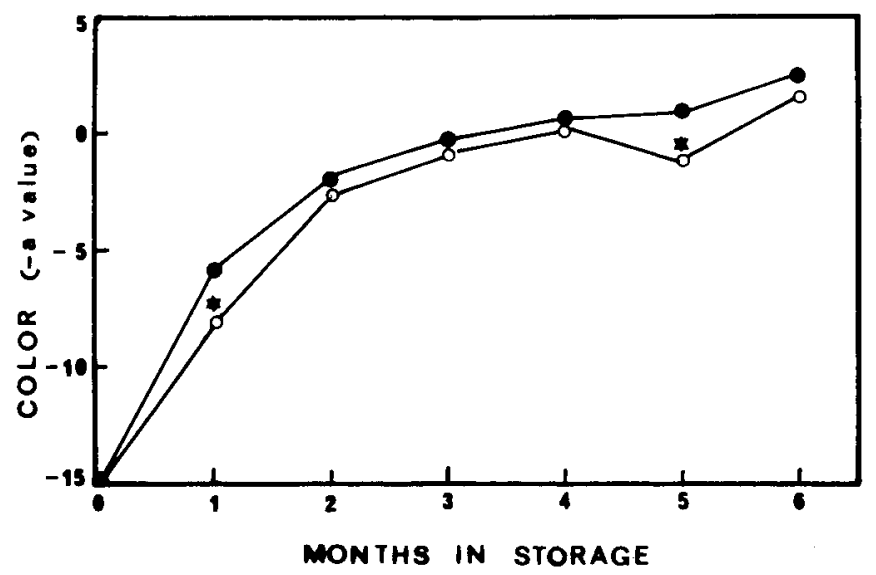

Fig. 4. Effect of seal-packaging in HDPE film on color of lemons stored at $13 \mathrm{C}$ for up to 6 months, followed by 1 week at $17 \mathrm{C}$. $\bullet=$ nonsealed; $O=$ seal-packaged. *Significant differences between treatments, $P=0.05$. 


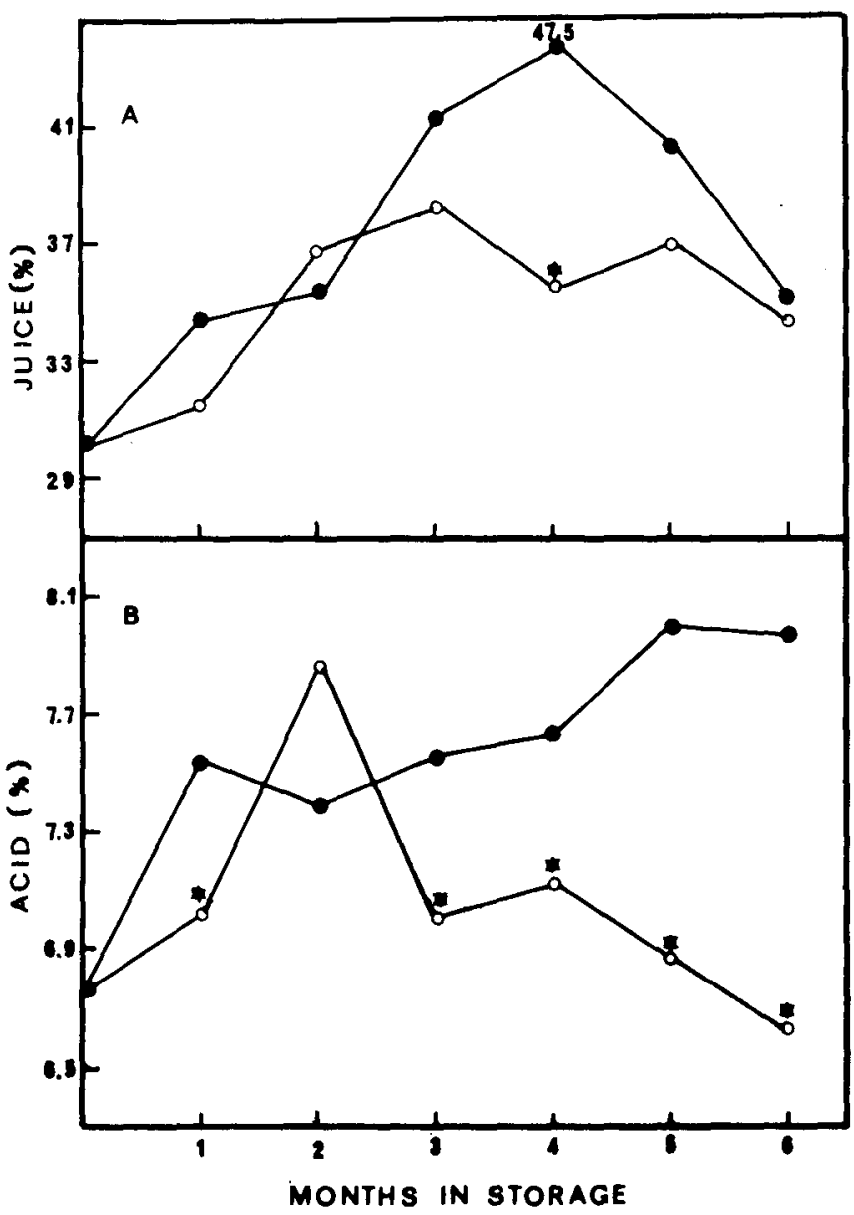

Fig. 5. Effect of seal-packaging in HDPE film on lemons stored at $13 \mathrm{C}$ for 1 to 6 months, followed by 1 week at 17C. (A) Percent juice expressed. (B) Acidity of the juice. $\bullet=$ nonsealed; $0=$ sealpackaged. *Significant difference between treatments, $P=0.05$.

during the first 3 months of storage in either treatment (Fig. 6C). After the 3rd month, the juice electrolyte conductivity began to increase in both treatments. However, in sealed fruits, this increase stopped after the 5th month, while in nonsealed fruits it continued. This increase in conductivity, which reflected an increase in the juice electrolyte content, may be a result of either changes in membrane permeability or release of ions from cell wall components during softening. Changes in membrane permeability often accompany senescence (Ben-Yehoshua, 1985; Ben-Yehoshua et al., 1983). It appears that senescence is more advanced in nonsealed lemons than in sealed lemons after extended periods of storage.

The difference in ethanol content of the juice of sealed and nonsealed fruit was more pronounced than that in electrolyte content (Fig. 6C). It was suggested more than 60 years ago that the alcohol content of citrus fruit may serve as a measure of the internal quality of the fruit (Onslow and Barker, 1928). Various studies have related the increase in ethanol content to fruit maturity, storage conditions, waxing, and modified atmosphere (Albrigo and 'Fellers, 1983; Ben-Yehoshua, 1985; Davis, 1970; Stein et al., 1986). The finding that the seal-packaged fruit did not develop increased ethanol is an indication that HDPE sealing allowed for adequate gas exchange.

Carbon dioxide production of sealed and nonsealed fruits increased in both treatments as storage progressed (Fig. 7A). Also,

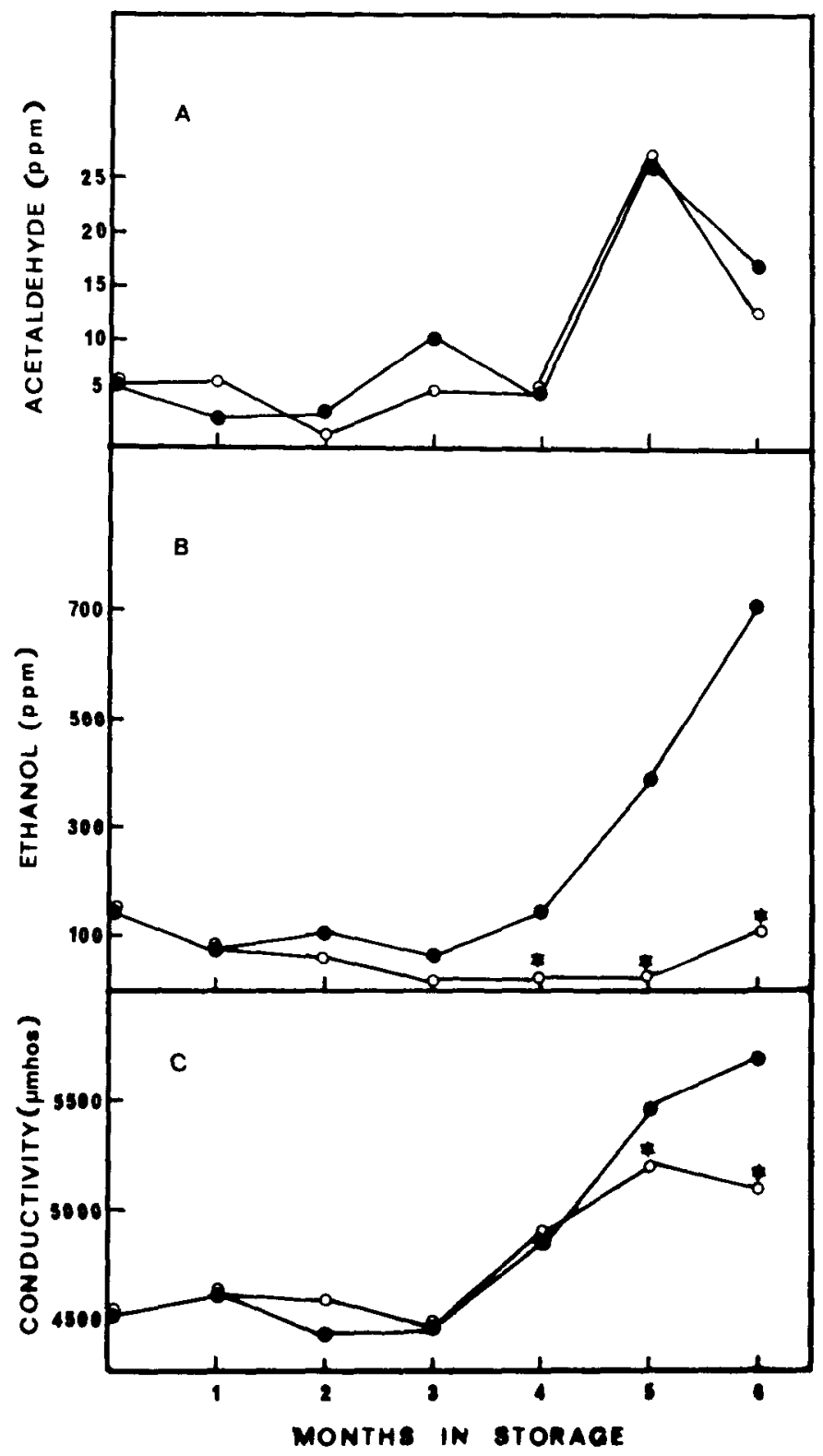

Fig. 6. Effect of seal-packaging in HDPE film on juice constituents from lemons stored at $13 \mathrm{C}$ for 1 to 6 months, plus 1 week at $17 \mathrm{C}$. (A) Acetaldehyde. (B) Ethanol. (C) Electrolyte conductivity. $\bullet=$ nonsealed; $O=$ seal-packaged. *Significant differences between treatments, $P=0.05$.

sealed lemons had consistently lower, but not significantly different, respiration rates than the controls. Ethylene production, however, was consistently lower in the nonsealed than in the sealed lemons after storage and shelf life, except after 1 month of storage.

The fruit developed very few blemishes or rots during the course of the experiment. During storage and shelf life, molds caused by Penicillium digitatum and P. italicum developed to a small extent (not more than $2 \%$ ), with no difference between sealed and nonsealed fruit. Molding fruit were excluded from evaluations since they could affect ethylene production, respiration rates, and firmness measurements.

The quality of seal-packaged lemons was higher after 6 months of storage than nonsealed lemons. Thus, seal-packaging of lemons after normal packinghouse procedures appears to be feasible and allows for storage of 6 months, and perhaps longer. 


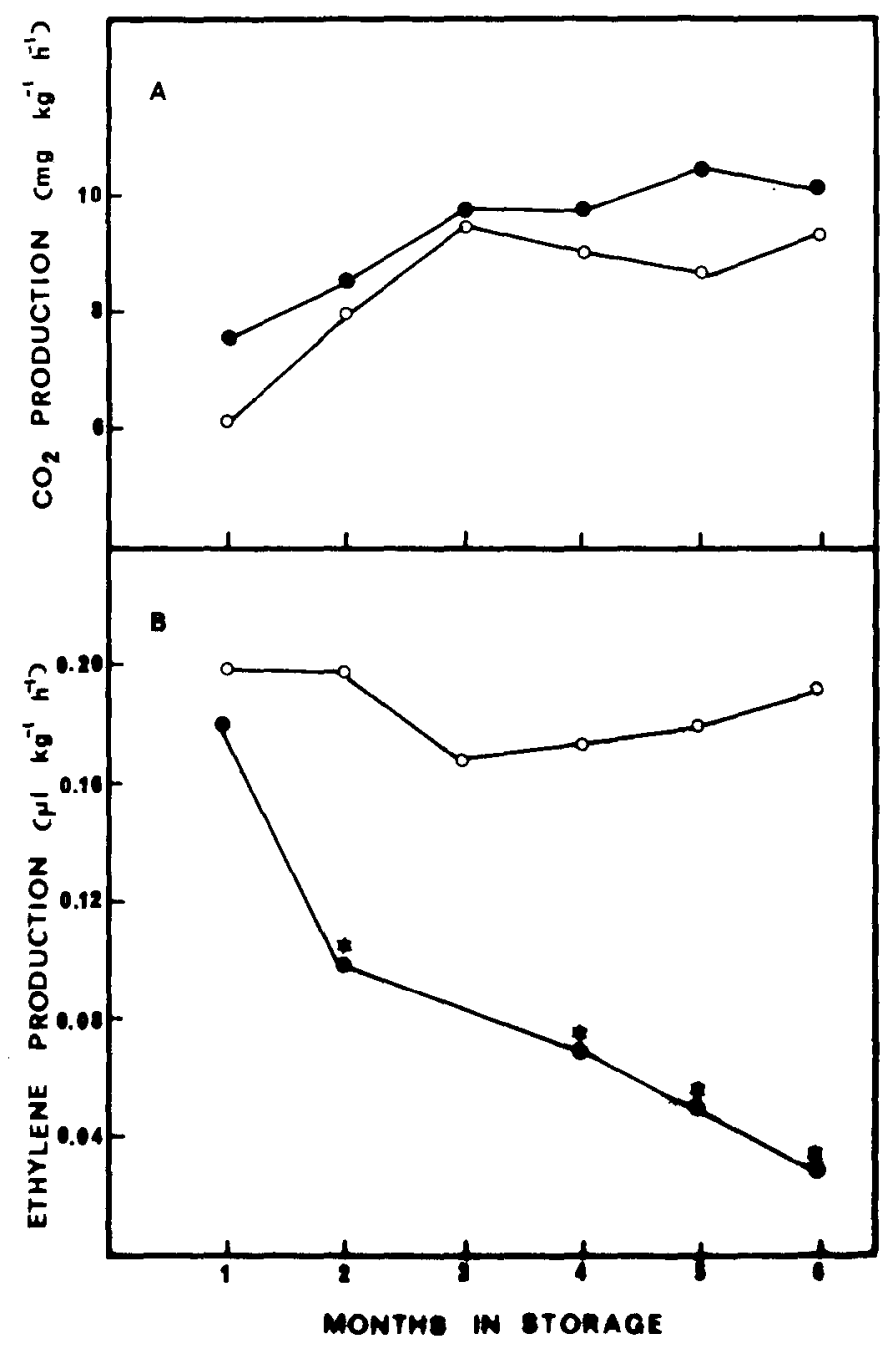

Fig. 7. Effect of seal-packaging in HDPE film on (A) $\mathrm{CO}_{2}$ and (B) ethylene production from lemons stored from 1 to 6 months at $13 \mathrm{C}$, plus 1 week at $17 \mathrm{C}$. $\bullet=$ non-sealed; $O=$ seal-packaged. ${ }^{*}$ Significant differences between treatments, $P=0.05$.

\section{Literature Cited}

Albrigo, L.G. and P.J. Fellers. 1983. Weight loss, ethanol, $\mathrm{CO}_{2}$ and $\mathrm{O}_{2}$ of citrus fruit wrapped in different plastic films. HortScience 18:101. (Abstr.)

Albrigo, L.G. and M.A. Ismail. 1983. Potential and problems of filmwrapping citrus in Florida. Proc. FIa. State Hort. Sci. 96:329-332.

Barmore, C. R., A.C. Purvis, and P.J. Fellers. 1983. Polyethylene film packaging of citrus fruit: Containment of decaying fruit. J. Food Sci. 48:1558-1559.

Ben-Yehoshua, S. 1969. Gas exchange, transpiration and the commercial deterioration in storage of orange fruit. J. Amer. Soc. Hort. Sci. 94:524-528.

Ben-Yehoshua, S. 1985. Individual seal-packaging of fruit and vegetables in plastic film-a new postharvest technique. HortScience 20:32-37.

Ben-Yehoshua, S., I. Kobiler, and B. Shapiro. 1979. Some physiological effect of delaying deterioration of citrus fruit by individual seal-packaging in high density polyethylene film. J. Amer. Soc. Hort. Sci. 104:868-873.

Ben-Yehoshua, S., I. Kobiler, and B. Shapiro. 1981. Effects of cooling versus seal-packaging with HDPE on keeping qualities of various citrus cultivars. J. Amer. Soc. Hort. Sci. 106:536-540.

Ben-Yehoshua, S., B. Shapiro, Z. Even-Chen, and S. Lurie. 1983. Mode of action of plastic film in extending life of lemon and bell pepper fruits by alleviation of water stress. Plant Physiol. 73:87-93.

Burger, D.W. and R.M. Davis. 1986. Effect of film wrapping on postharvest decay incidence of Texas grapefruit. J. Rio Grande Valley Hort. Soc. 39:23-30.

Cohen, E. 1988. Commercial use of long term storage of lemon with intermittent warming. HortScience 23:400-401.

Cohen, E. and M. Schiffmann-Nadel. 1978. Storage capability at different temperatures of lemons grown in Israel. Scientia Hort. 9:251257.

Cohen, E., M. Schiffmann-Nadel, S. Monselise, R. Goren, and M. Uziel. 1979. Prolonging the picking season of lemon fruits by sprays with growth retardants (in Hebrew). Alon HaNotea 34:65-69.

Cohen, E., M. Shuali, and Y. Shalom. 1983. Effect of intermittent warming on the reduction of chilling injury of lemon fruit stored at cold temperature. J. Hort. Sci. 58: 122-127.

Davis, P. 1970. Relation of ethanol content of citrus fruit to maturity and to storage conditions. Proc. Fla. State. Hort. Sci. 30:294-297.

Eaks, I.L. and E. Masias. 1965. Chemical and physiological changes in lime fruits during and after storage. J. Food Sci, 30:509-515.

Gallasch, P.T. 1981. Growth regulators for promotion of on tree storage of grapefruit and HDPE storage of harvested fruit. Proc. Intl. Soc. Citricult., Tokyo. 1:229-233.

Golumb, A., S. Ben-Yehoshua, and Y. Sarig. 1984. HDPE wrap improves wound healing and lengthens shelf-life of mechanically harvested grapefruit. J. Amer. Soc. Hort. Sci. 109:155-159.

Hale, P. W., T.T. Hatton, Jr., and L.G. Albrigo. 1981. Exporting individually packaged grapefruit in bulk bins and nonpackaged grapefruit in bulk bins with film liners. J. Food Distrib. Res. Sept. p. 9-18.

Kawada, K. and L.G. Albrigo. 1979. Effect of film packaging, in carton air filters, and storage temperatures on the keeping quality of Florida grapefruit. Proc. Fla. State Hort. Soc. 92:209-212.

Kawada, K. and P.W. Hale. 1980. Effect of individual film wrapping and relative humidity on quality of Florida grapefruit and condition of fiberboard boxes in simulated export tests. Proc. Fla. State Hort. Soc. 36:67-71.

Onslow, M. and J. Barker. 1928. The alcoholic content of oranges and its diagnostic value. Great Britain Food Investigations Board Rpt. for 1927. p. 35-36.

Purvis, A.C. 1983a. Moisture loss and juice quality from waxed and individually seal-packaged citrus fruit. Proc. Fla. State Hort. Soc. 96:327-329.

Purvis, A.C. 1983b. Effect of film thickness and storage temperature on water loss and internal quality of seal-packaged grapefruit. $\mathrm{J}$. Amer. Soc. Hort. Sci. 108:562-566.

Sharkey, P. J., C.R. Little, and I.R. Thornton. 1985. Effect of low density polyethylene liners and HDPE wraps on quality, decay and storage life of lemon and tangor fruits. Austral. J. Expt. Agr. 25:718721.

Sharkey, P.J. and I.D. Peggie. 1984. Effect of high humidity storage on quality, decay and storage life of cherry, lemon and peach fruits. Scientia Hort. 23:181-190.

Sinclair, W. 1984. The biochemistry and physiology of the lemon. Univ. of California Press, Oakland.

Stein, E.R. 1986. Juice quality of stored polyethylene seal-packaged grapefruit. J. Rio Grande Valley Hort. Soc. 39:31-39.

Stein, E. R., H.E. Brown, and R.R. Cruse. 1986. Seasonal and storage effects on color of red fleshed grapefruit juice. J. Food Sci. 51:574576.

TugWell, B.L. and K. Gillespie. 1981. Australian experience with citrus fruits wrapped in high density polyethylene film. Proc. Intl. Sot. Citricult., Tokyo. 2:710-714, 